\title{
Electric and Motor Responses of the Weakly Electric Fish, Gnathonemus petersii (Mormyridae), to Play-back of Social Signals
}

\author{
Bernd Kramer \\ Fachbereich Biologie, Universität Konstanz, Postfach 5560, D-7750 Konstanz, Federal Republic of Germany
}

Received January 12, 1979 / Accepted April 30, 1979

Summary. 1. Seven isolated G. petersii resting in their daytime hiding-places were stimulated via a dipole model (Fig. 1 a) with previously tape-recorded electric organ discharge (EOD) patterns in an attempt to determine whether $G$. petersii distinguishes two different intraspecific EOD patterns, rest and attack.

2. Rest pattern A was characterized by a broad distribution of EOD intervals, a low mean discharge rate $(8 \mathrm{~Hz}$, Fig. 3$)$, and a long period of significantly positive autocorrelation ( $2 \mathrm{~s}$, Fig. $4 \mathrm{a})$. Accordingly, the spectrum of EOD rate fluctuations showed a low frequency range $(0.005$ to $0.12 \mathrm{~Hz}$, Fig. $5 \mathrm{a})$. Attack pattern $\mathrm{B}$ was a considerably different EOD interval distribution of high mean discharge rate $(25 \mathrm{~Hz}$, Fig. 3), showing a short period of significantly positive autocorrelation $(0.8 \mathrm{~s}$, Fig. $4 \mathrm{~b})$, only. Here, the spectrum of EOD rate fluctuations was at a considerably higher frequency range $(0.09$ to $0.47 \mathrm{~Hz}$, Fig. 5 b).

3. Play-back of attack pattern B elicited significantly more bodily startle responses from the experimental fish (Fig. 6) than did the rest pattern A (Table 1). Also the number of attacks directed at the dipole model was significantly greater during stimulation with attack pattern B (Table 2, Fig. 6).

4. The EOD responses of the experimental fish differed in several respects depending on which stimulation pattern was used. The modes of the pulse rate histograms as well as their spans were lower during play-back of rest pattern $\mathrm{A}$ than during stimulation with attack pattern B (average 12.3 vs $16.2 \mathrm{~Hz}$, and average 47 vs $56 \mathrm{~Hz}$, respectively; Fig. 11). Shortterm $(0.2 \mathrm{~s})$ EOD rate correlations were stronger when the fish were stimulated with rest pattern A than when they were stimulated with attack pattern B (average correlations 0.67 and 0.61 , respectively; Figs. 10 and 11). Significant positive correlations were maintained for longer periods of time during rest pat- tern stimulation than during attack pattern stimulation (average 1.94 and $1.24 \mathrm{~s}$, respectively; Figs. 10 and 11). The spectra of EOD rate fluctuations of the stimulated fish were at lower frequency ranges during rest pattern stimulation than during attack pattern stimulation (average amplitude-spectrum peak frequencies 0.02 and $0.07 \mathrm{~Hz}$, respectively; Figs. 12 and 13).

5. Although maximal cross-correlations from the EOD rates to the stimulus pulse rates were weaker during rest pattern stimulation (average 0.2 ) than during attack pattern stimulation (average 0.33), significant cross-correlations were maintained for longer periods of time during rest pattern stimulation than during attack pattern stimulation (average 1.78 and $0.92 \mathrm{~s}$, respectively). The lags of maximal cross-correlations were greater during rest pattern stimulation than during attack pattern stimulation (average 2.6 and $0.8 \mathrm{~s}$, respectively; Figs. 14 and 15).

6. The results clearly showed that at least two specific EOD time patterns encode different 'messages' in the intraspecific communication system of $G$. petersii.

\section{Introduction}

The observations by Möhres (1957) and Szabo (1961) first suggested that the African group of weakly electric fishes, the Mormyridae, might use their electric organ discharges (EODs) for communication. The experimental analysis of this hypothesis began with investigations showing that the fish responded to various kinds of stimuli, including electrical, with discharge rate changes (Harder et al., 1967; Sänger, 1972; Moller, 1970; Serrier, 1973; Bauer, 1974).

Experiments dealing more specifically with electric 
communication and social behaviour were made by Bauer (1972), Moller and Bauer (1973), Bauer and Kramer (1974), Kramer (1974, 1976a and b), Bell et al. (1974), Russell et al. (1974), Kramer and Bauer (1976) and Moller (1976). Specific EOD patterns related to patterns of social behaviour were observed. Interacting fish exhibited time-related discharge rate changes. The preferred latency response of Gnathonemus petersii, a statistically significant preference for an EOD delay of approx. 10-12 $\mathrm{ms}$ to foreign pulses, was interpreted as a mechanism aiding the fish to separate their own signals from foreign signals (jamming avoidance). Similar responses have been found in other mormyrid species (Heiligenberg, 1976, 1977), not always compatible with the jamming avoidance hypothesis (Kramer, 1978).

In a denervation experiment the absence of EODs in a partner was shown to greatly increase the amount of internal constraint (i.e., dependence of the probability of occurrence of a given act on earlier acts) in the motor pattern sequence exhibited by a recipient $G$. petersii, compared with the presence of an electrically intact conspecific (Kramer, 1976c). From these experiments it was concluded that information was transmitted by conspecific electric signals which significantly influenced the behaviour of a recipient $G$. petersii.

G. petersii exhibits several types of EOD patterns related to motor activity (Belbenoit, 1972; Bauer, 1974) and to various kinds of social interactions between partners (Kramer and Bauer, 1976; Kramer, 1976b), as do several other mormyrids (Kramer, 1978). In a communication system it may be expected that a set of different signals serve the partners for communicating different messages.

This hypothesis was tested by play-back experiments in the present work. Two different taperecorded EOD patterns were played back via a dipole model to the experimental subjects, which were not stimulated otherwise. Contrary to the stimulation experiments cited, the dipole model was devised to reproduce the electric field of a $G$. petersii as closely as possible in the present work.

One of the two stimulation patterns (A) was a resting discharge activity, the other pattern (B) was the EOD activity recorded from an attacking $G$. petersii which displayed high discharge rates.

Motor behaviour responses of the experimental subjects were filmed by a video recording system. The EOD responses were analyzed by autocorrelation and cross-correlation, and by spectral analysis methods. The rationale of this approach was that numerical methods capable of handling large amounts of data were required in order to detect quantitative differences in patterns of responses obscured by noise.

\section{Materials and Methods}

Seven Gnathonemus petersii (12-17 cm standard length) were used in this study. Before the experiments the animals were maintained together in a 360-1 aquarium which was planted and contained many porous-pot hiding-places. The water was power-filtered by synthetic fibre and peat, and the temperature was $26^{\circ} \mathrm{C}$. Electrical resistivity ranged from 2.5 to $2.9 \mathrm{k} \Omega \cdot \mathrm{cm}$, and $\mathrm{pH}$ was near 7 . A 12-h/12-h light-dark cycle from 0700 to 1900 hours was used both for the experimental and the home tanks. The fish were fed daily on live Chironomus larvae or Tubifex worms.

Prior to the beginning of an experiment the animals were habituated to the experimental tank $(1.0 \times 0.5 \times 0.5 \mathrm{~m}, 2501)$ for at least 4 days. When the animal under study had accepted its hiding-place for most of the time during day, a 5-day series of play-back experiments started.

Two experiments per day were performed at 0900 hours and 1700 hours. In random order, one of two different EOD activity patterns stored on magnetic tape was played back via a dipole model, with the restriction that no pattern was played back twice a day. The EOD activity pattern $\mathrm{A}$ had previously been recorded from a resting, isolated $G$. petersii; the EOD activity pattern B had previously been recorded from an animal vigorously attacking a Mormyrus rume while displaying attack-associated high discharge rates (Figs. 3--5).

The stimulus field was generated by a Grass S 88 stimulus generator connected to the dipole model via a stimulus isolation unit (Grass SIU 5). No attempt was made to reproduce the EOD wave-form; instead, the wave-form produced by the dipole was a slightly 'rounded' 0.5 -ms monopolar square-wave pulse (Fig. 1 b). Heiligenberg (1976) had shown in Brienomyrus niger that stimulation with square-wave pulses similar to those used in the present study yielded the same results compared with sine-wave pulses adjusted to resemble natural EODs more closely, except for the square-wave pulses appearing slightly more efficient. The stimulus pulses were triggered by tape-recorded EODs as schematically shown in Fig. 2.

The hiding-place was a $16.5-\mathrm{cm}$ length of porous pot with a $6.5 \mathrm{-m}$ inner diameter. As this pot was closed at one end by coarse plastic mesh, the fish stayed in a rather precisely specified position within the pot, with its chin appendage protruding slightly out of the open end (Fig. 1a). The polarity of the stimulating field was chosen such that the field of a conspecific in antiparallel position to the fish was reproduced (i.e., the electrical 'head' of the dipole was near the tail of the fish). A modified dipole with three electrodes was used, which gives a good approximation of the electric field produced by G. petersii (Boundinot, 1972). The field intensity produced by the dipole inside the porous pot at a distance of $5 \mathrm{~cm}$ from the dipole (which was the distance dipolebody wall of the fish facing the dipole) is shown in Fig. $1 \mathrm{c}$ (measured with the fish not in place). The amplitude of the stimulating field was regulated such that it was equal to the p-p EOD voltage of fish A which was used first in the study. The same amplitude was used throughout the study. The stimulus amplitude perceived by the fish in its hiding-place was approx. $36 \mathrm{~dB}$ above threshold. The threshold criteria were: "discharge arrest' or 'sudden discharge rate increase with regularization' (concerning regularization, cf. Moller, 1970).

Details of the experimental set-up are given in Fig. 2. A1"video system (Grundig BK 300) with two cameras (Grundig FA 70) was used. One camera monitored the lateral and the bottom (mirror) view of the behaviour of the fish, and the other monitored the display of an electronic counter triggered by the EODs (the EODs were also recorded on the audio track of the vido tape). Thus each video picture was 'labelled' by the display of the EOD total from start of experiment. In this way, the separate video and audio records could easily be synchronized. 

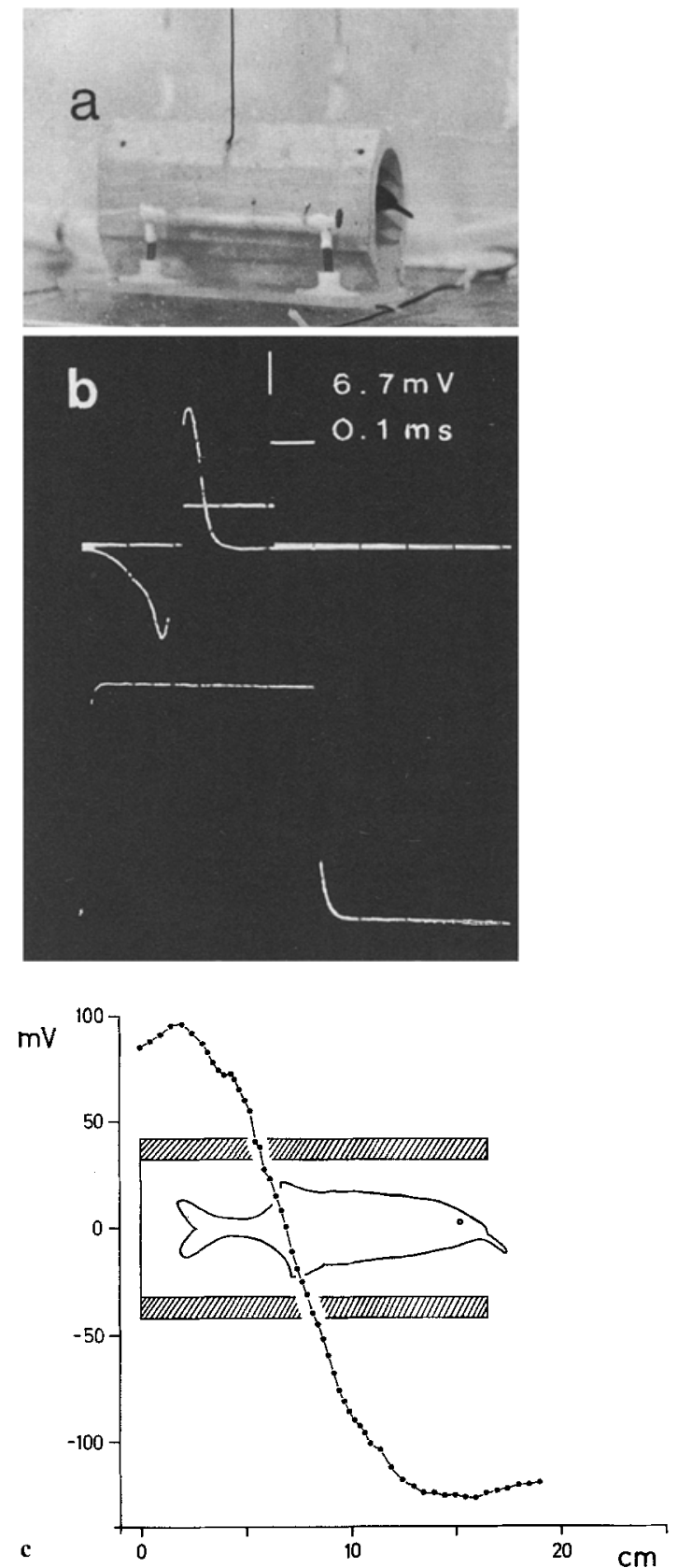

Fig. 1 a-c. Physical and electrical aspects of the stimulus conditions. a The daytime hiding-place of the fish with the dipole model $5 \mathrm{~cm}$ from the right body wall of the animal. The dipole model was a plexiglass rod with three $\varnothing 2.6$-mm ball electrodes (according to Boudinot, 1972). b Wave-forms of the electric organ discharges (EOD) of the fish and of the stimulus pulse seen by the same pair of electrodes $1 \mathrm{~m}$ apart, straddling the hiding-place and the dipole. Superimposed on the EOD is a logic pulse of 5-V amplitude triggered from the EOD. These pulses were stored on magnetic tape or were fed directly into a digital analyzer. The logic triggering point was delayed by $0.01 \mathrm{~ms}$ to the zero crossing of the rapid potential change of the EOD from head positivity to head negativity. c Intensity of the stimulus field at the body wall of the fish facing the dipole, measured inside the porous pot with the fish not in place. The reference electrode was on potential zero as far away as possible in the experimental $250-1$ aquarium
Stimulating

Apparatus I Recording Apparatus

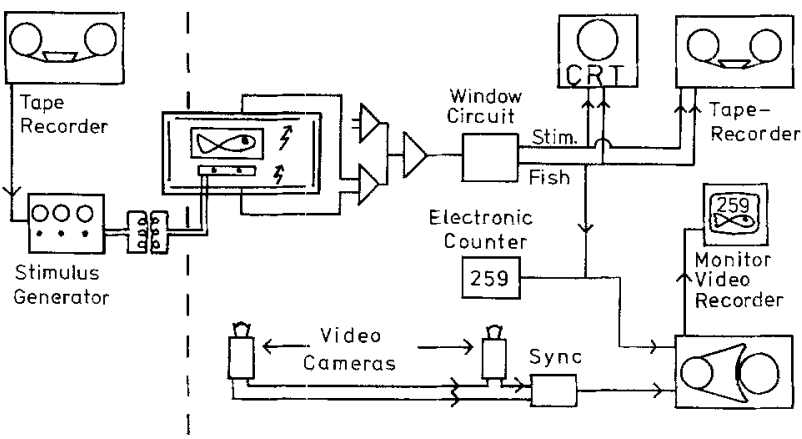

Fig. 2. Experimental set-up. The fish were stimulated with previously tape-recorded EOD pulse patterns via a dipole model. The tape-recorded pulses triggered square-wave pulses from a stimulus generator (see Fig. 1 b) connected to the dipole via a stimulus isolation unit. Stimulus pulses and EODs were picked up in the water from two pairs of orthogonal electrodes fixed on the walls of the tank. The signals from both pairs of electrodes were differentially amplified, rectified, and summed electronically. The times of occurrences of stimulus pulses and of EODs were discriminated by a 'window' circuit; thus separate recording of the two series of events on two tracks of a magnetic tape was possible. The behaviour of the fish and the concurrent display of an electronic counter triggered by the EODs were taped by a video recording system

The method of EOD recording was the same as described by Kramer (1974). The times of occurrences of EODs and of stimulus pulses were taped on different tracks of an instrumentation tape-recorder (Kyberna 601 ) at $9.5 \mathrm{~cm} / \mathrm{s}$ for off-line analysis by a digital analyzer. In order to analyze the relationships between the two time series of events, observations were made at discrete, equispaced time intervals which had to be strictly in register for both time series.

A method of data acquisition that allowed for these requirements was employed although a single-input digital analyzer (Nicolet 1074 with SH-71 and -72 plug-in modules) had to be used. The principle of this method (modified from that described by Kramer, 1974) was as follows: in parallel with the two series of experiment-generated events, recorded on separate tracks of the tape, a reference signal (short pulses separated by 0.2 -s intervals) was recorded on a third track of the tape. On a fourth track, start pulses (one single pulse for each record) were stored. Successive analysis of both records (of stimulus pulses and of EODs) by the digital analyzer was initiated by one specific start pulse from the tape (track four). The number of events occurring during a pair of tape-recorded reference pulses was counted by the digital analyzer and the results were placed into successive memory addresses.

The data stored in this device were output on $\mathrm{BCD}$ paper tape and read and the data transferred to magnetic tape files in the computer centre of the University of Konstanz. The data stored on these tapes were used as the input to programs written in Fortran IV, which performed various forms of time series analyses. The results were output on a digital plotter connected to the computer.

Numerical methods, described by Box and Jenkins (1976), were used to obtain autocorrelations and frequency spectra of pulse rate fluctuations, as well as cross-correlations of EOD pulse rates to stimulus puise rates. 
Following the above authors, the most satisfactory estimate of the $k$ th lag autocorrelation $\rho_{k}$ is

$r_{k}=\frac{c_{k}}{c_{0}}$

where

$c_{k}=\frac{1}{N} \sum_{t=1}^{N-K}\left(z_{t}-\bar{z}\right)\left(z_{t+k}-\bar{z}\right), \quad k=0,1,2, \ldots, K$

is the estimate of the autocovariance $\gamma_{k}, \bar{z}$ is the mean of the time series, and $z_{\mathrm{x}}$ is an observation at time $t$.

The standard errors of autocorrelation estimates were determined as the square roots of the estimated large-lag variances

$\operatorname{var}\left[r_{k}\right] \simeq \frac{1}{N}\left\{1+2 \sum_{k=1}^{q} r_{k}^{2}\right\} k>q$

for lags $k$ greater than some value $q$ beyond which the theoretical autocorrelation function is assumed to be zero.

The Fourier coefficients of a set of data points $z_{t}$ whose number was odd $(N=2 q+1)$ was calculated according to the method described by Box and Jenkins (1975):

$a_{i}=\frac{2}{N} \sum_{i=1}^{N} z_{t} \cos 2 \pi f_{i} t$

$b_{i}=\frac{2}{N} \sum_{t=1}^{N} z_{t} \sin 2 \pi f_{i} t, \quad i=1,2, \ldots, q$

where $f_{i}=i / N$ is the $i$ th harmonic of the fundamental frequency $1 / N$.

From the coefficients the amplitudes of the frequencies $f_{i}$ were calculated

$A\left(f_{i}\right)=\frac{N}{2}\left(a_{i}^{2}+b_{i}^{2}\right), \quad i=1,2, \ldots, q$.

As the smallest period of a sinusoidal component is two observation intervals (i.e., $0.4 \mathrm{~s}$ ), the highest frequency that could be detected was $2.5 \mathrm{~Hz}$ in the present study.

The $k$ th lag cross-correlation coefficient $\rho_{x y}(k)$ was estimated by

$r_{x y}(k)=\frac{c_{x y}(k)}{s_{x} s_{y}}, \quad k=0,1,2, \ldots$

where the estimate of the cross-covariance coefficient is

$c_{x y}(k)=\frac{1}{n} \sum_{t=1}^{n-k}\left(x_{t}-\bar{x}\right)\left(y_{t+k}-\bar{y}\right), \quad k=0,1,2, \ldots$

where $\bar{x}, \bar{y}$ are the means of the $x$ series and $y$ series, respectively, with their associated standard deviations $s_{x}$ and $s_{y}, x_{t}$ and $y_{t}$ are observations of the $x$ series and the $y$ series at time $t$, and $n$ is the number of observations.

Non-parametric statistical tests such as the Wilcoxon matchedpairs signed-ranks test and the randomization test for matched pairs were used according to the method described by Siegel (1956). All values for $P$ given in this paper refer to two-tailed regions of rejection of the sampling distributions.

\section{Results}

\section{Time Series Analysis of the Stimulus Patterns}

The fish were stimulated with pulse sequences previously recorded from conspecifics. Figures 3-5 describe the properties of the two stimulus patterns.
Stimulus pattern $\mathrm{A}$ had been recorded from a resting animal, stimulus pattern $B$ from an attacking animal. Rest pattern $A$ is a broad distribution of EOD intervals with three weak modes (Fig. 3a). Attack pattern $\mathrm{B}$ is characterized by a bimodal EOD interval distribution with a very sharp gap separating the two modes (Fig. 3a; cf. also Kramer and Bauer, 1976).

The distributions of discharge rates of patterns $A$ and $B$ are shown in Fig. 3 b. Pattern $A$ is confined to a rather narrow range of discharge rates between 2.5 and $40 \mathrm{~Hz}$ with the peak at $7.5 \mathrm{~Hz}$. Discharge rates occurring during attack pattern $B$ reach $5-112.5 \mathrm{~Hz}$, while the discharge rate measured most often was $15 \mathrm{~Hz}$.

Insight into the kinds of time regulation of discharge rate changes may be gained by autocorrelation methods and by spectral analysis of the sequential pulse rate data (examples are shown in Figs. 8 and 9).

Figure 4 shows the autocorrelation functions of the pulse rates of the two stimulus patterns. In rest pattern $A$, pulse rate remained above or below the mean for ten successive observations (i.e., 2.0 s) since nine coefficients were significantly positive; after that time no correlation was found (coefficients were not significantly different from zero). Superimposed on this model was an alternating discharge rate change between adjacent observation periods (i.e., from one 0.2 -s observation period to the next one) since the second coefficient was higher than the first one. The cause for this was an alternating EOD interval-length regulation between adjacent EOD intervals (cf. Kramer, 1974). So the discharge rate of the next observation but one was more similar to the first observation than the one between these two observations.

In attack pattern $B$, pulse rates remained above or below the mean for a considerably shorter time only. After four observation periods (i.e., $0.8 \mathrm{~s}$ ), pulse rate was no longer correlated with respect to the first observation since only three coefficients were significantly different from zero. Contrary to pattern A, in pattern $B$, pulse rates of adjacent observation periods were very strongly correlated since the autocorrelation function started with a very high coefficient of 0.76 .

A different approach to the analysis of a series of observations of a variable which changes in time is an estimation of the amplitudes of sinusoidal components of unknown frequencies buried in noise.

The spectrum of the rest-pattern discharge rate fluctuations showed high amplitudes (above $1 / 3$ of the peak amplitude) in a frequency range of 0.005 to $0.12 \mathrm{~Hz}$; the peak was at $0.041 \mathrm{~Hz}$ (Fig. 5a). The spectrum of attack pattern $B$ showed $1 / 3$ peak amplitudes within a considerably higher frequency range from 0.09 to $0.47 \mathrm{~Hz}$; the peak was at $0.23 \mathrm{~Hz}$ (Fig. 5b). 


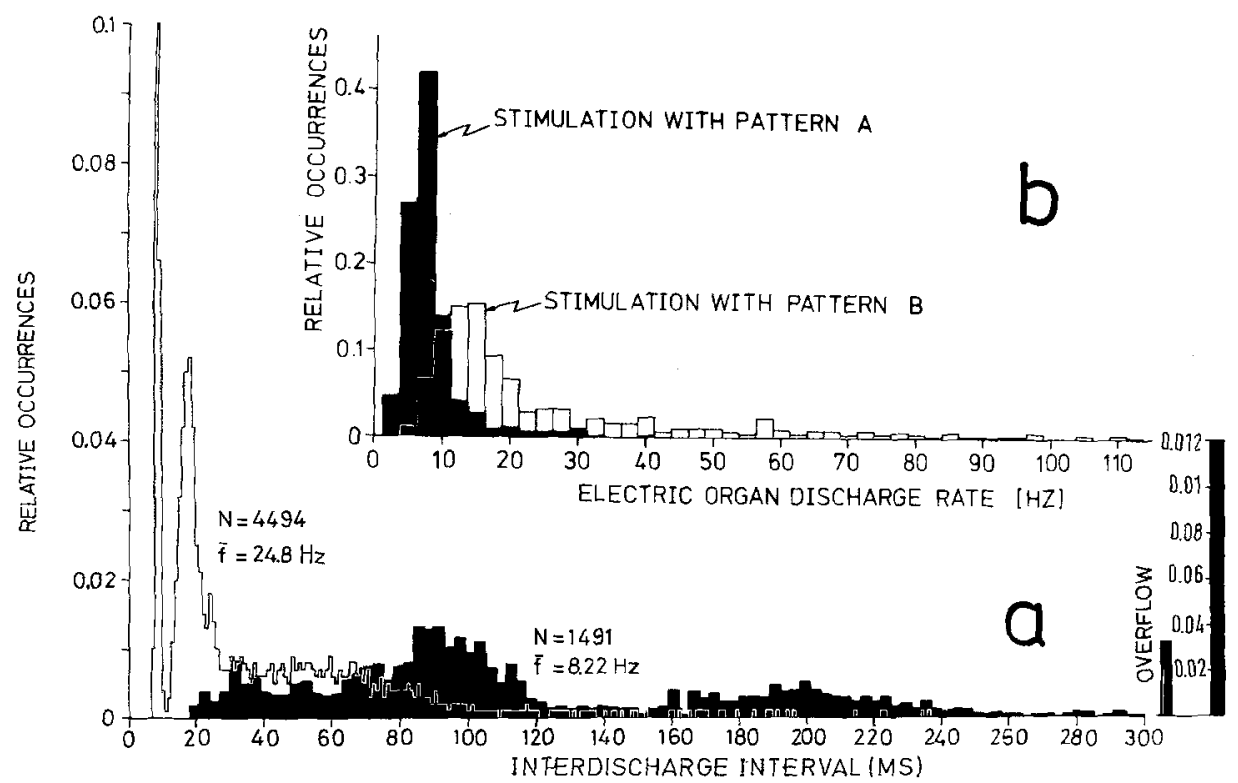

Fig. 3a and b. EOD patterns used for 3-min stimulation periods of the experimental fish via the dipole model. a EOD interval histograms. Stimulus pattern A (black histogram) is the discharge activity of a resting G. petersii (3-ms bins). Stimulus pattern B (white histogram) is the discharge activity of a $G$. petersii attacking and pursuing a partner (1-ms bins). Abscissa: discharge interval (ms); ordinate: relative occurrences of intervals of a specific bin width (black ordinate is for black histogram). $N$, total number of intervals; $f$, mean discharge rate. b EOD rate histograms. Abscissa: EOD rate (2.5-Hz bins); ordinate: relative occurrences of a specific EOD rate
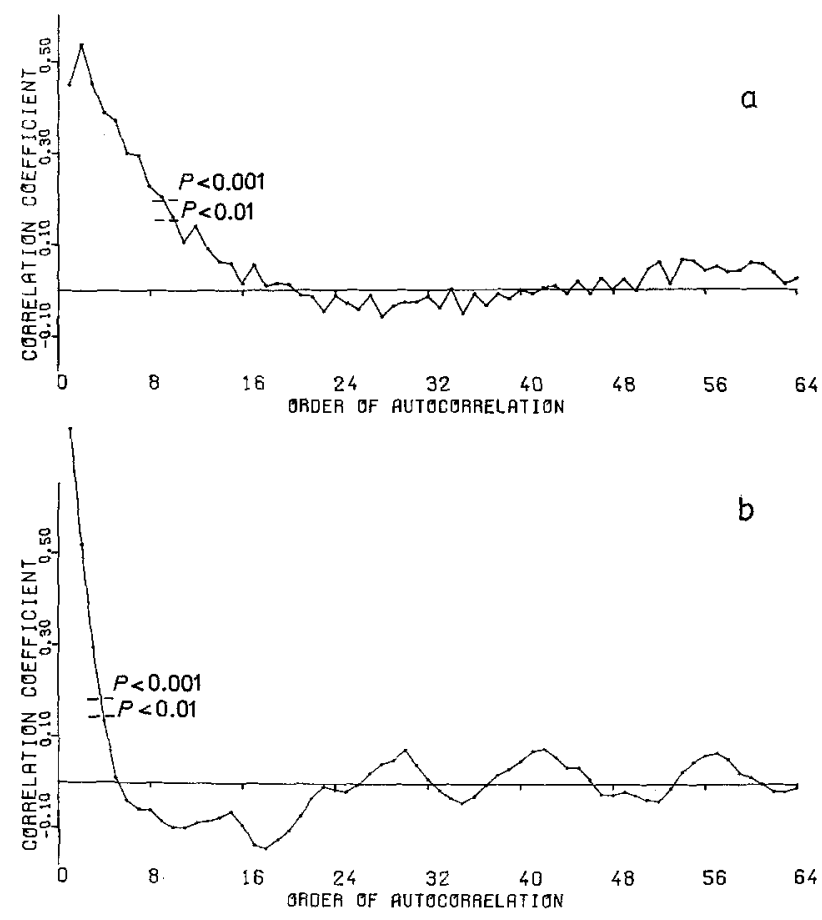

Fig. $4 \mathbf{a}$ and $\mathbf{b}$. Autocorrelation analysis of the pulse rates of rest and attack stimulation patterns $A(a)$ and $B(b)$. Note that the autocorrelation function of attack pattern $B$ starts with a high coefficient but declines more steeply than does the autocorrelation function of rest pattern $A$. The positive pulse rate correlation of attack pattern $B$ 'dies out' within $0.8 \mathrm{~s}(\hat{=} 3$ significant coefficients $P<0.001$ ), whereas pulse rates of rest pattern A are positively correlated for $2 \mathrm{~s}$ ( $\triangleq 9$ significant coefficients). Superimposed on this pulse rate regulation is a short-term $(0.2 \mathrm{~s})$ pattern of pulse rate change in rest pattern $\mathrm{A}$, since the second coefficient is higher than the first
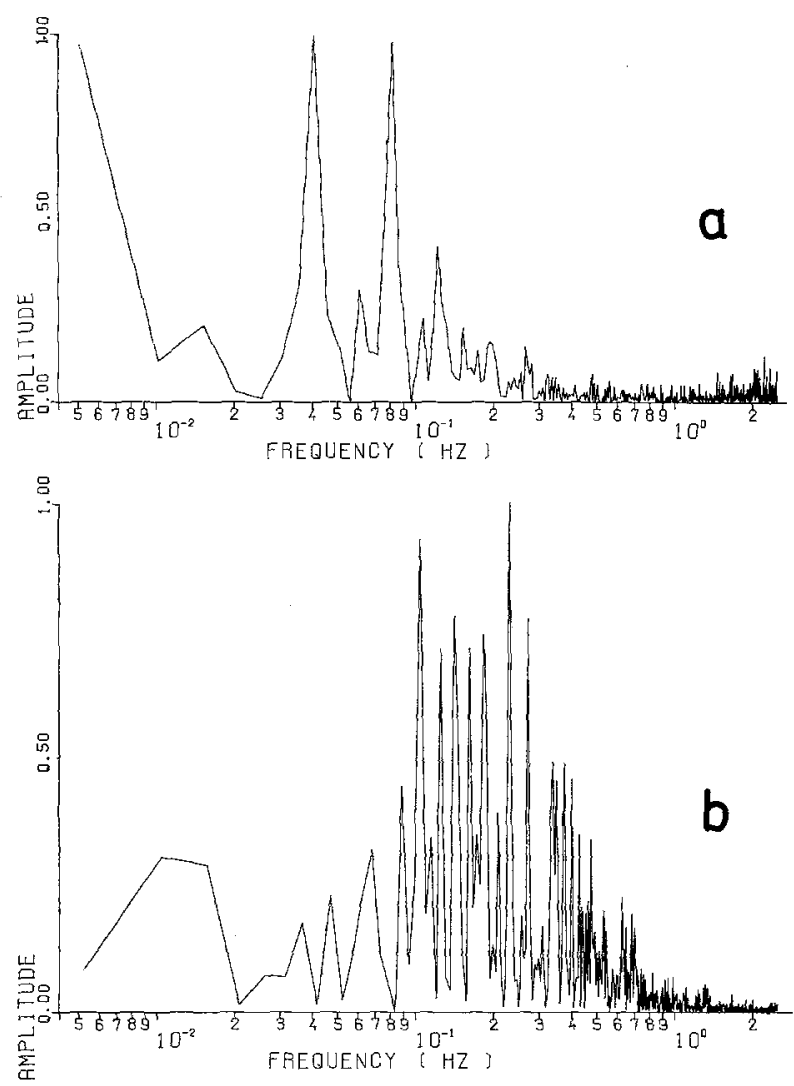

Fig. 5a and b. Amplitude spectrum analysis of the pulse rate fluctuations of attack patterns $A$ (a) and B (b). Ordinate: amplitudes of sinusoidal components in arbitrary units; abscissa: frequency in $\mathrm{Hz}$. Note that the attack stimulation pattern $\mathrm{B}$ shows significant amplitudes at a considerably higher frequency range than does the rest stimulation pattern $A$ 

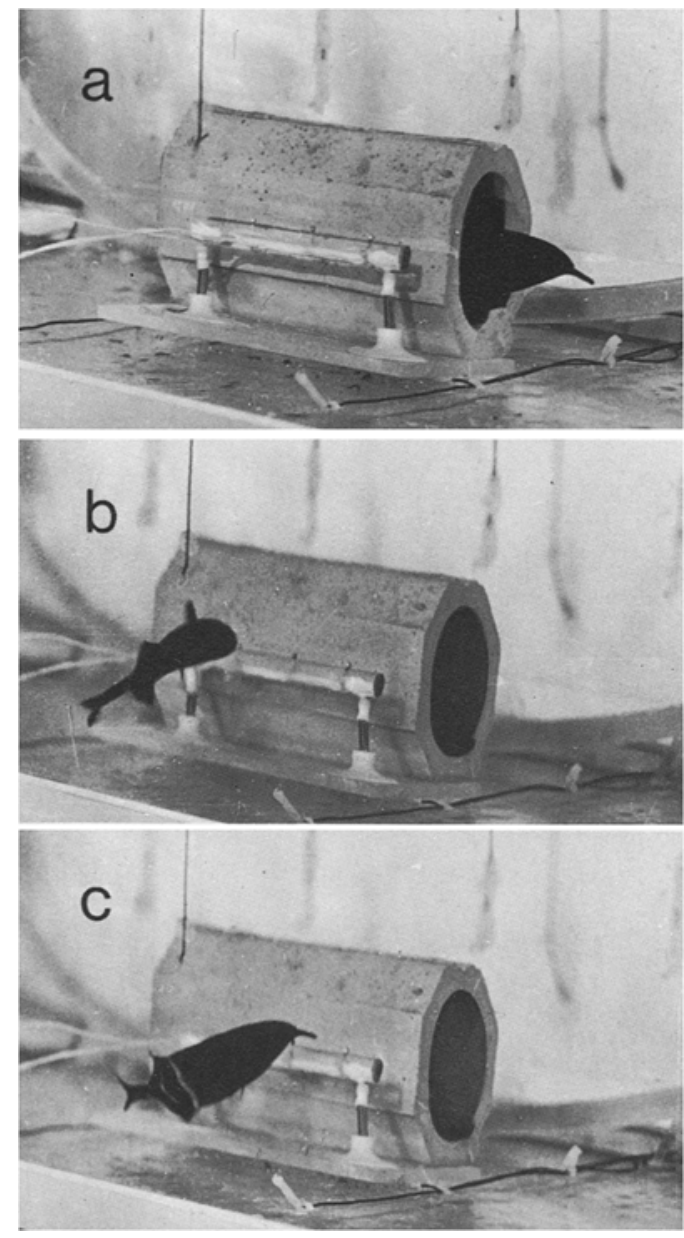

Fig. 6a-c. Motor responses of $G$. petersii on play-backs of social signals via a dipole. a Startle responses were observed significantly more often during stimulation with attack pattern $B$ compared with rest pattern A. A startle response was a rapid forwards and backwards movement during which the fish never totally left its porous-pot hiding-place. b Attack responses on the dipole model were observed significantly more often during stimulation with attack pattern B. cIn many instances a Lateral Display accompanied by a high discharge rate followed the attack responses in the same manner as observed during social behaviour

\section{Motor Responses of the Fish to the Stimulation with the Dipole Model}

Various kinds of motor responses were observed at onset of stimulation of the fish resting in their hidingplaces (Fig. 1 a). The most frequent response observed was a bodily startle response (Fig. 6a) with discharge rate increase. Another kind of response was an attack response on the dipole, which was sometimes followed by a lateral display with high discharge rate (Fig. 6b and c; cf. Kramer and Bauer, 1976). Various other kinds of behaviour were also observed during stimulation (e.g., swimming restlessly about the aquarium, probing the dipole model intensely with the chin ap- pendage for more or less sustained periods of time and swimming in rapid bouts near the bottom of the aquarium). No effort was made to quantify these complex behaviours; the number of startle responses and of attacks on the dipole model, however, could easily be determined from slow-motion play-backs of the video tapes.

Table 1 shows the outcomes of the startle response analysis separately for each fish. In each animal and every paired observation the rate of startle responses per second, displayed by the animal inside its hidingplace, was found to be higher during stimulation with attack pattern $B$ than during stimulation with rest pattern A. The finding was significant individually for all of those five out of seven animals for which sufficient observations were available $(P<0.05$, twotailed randomization test for matched pairs). Pooling of the data yielded a $P \ll 0.001$ (randomization test for matched pairs, two-tailed).

Except for two animals which never attacked the dipole model, all other animals (i.e., five) attacked the dipole model either significantly more often (fish A; $P<0.05$, two tailed randomization test for matched pairs) or exclusively during stimulation with attack pattern B (animals C, E, F, and H, Table 2). An analysis of the attack totals of all fish also yielded a significant difference for rest and attack pattern stimulation $(P<0.05$; two-tailed randomization test for matched pairs). The reason no attack was observed in many paired experiments was that the fish did not leave their hiding-places (these experiments are marked by an asterisk).

\section{EOD Responses to the Stimulus Patterns}

The previous section on motor behaviour described attack responses of the fish towards the dipole model. Associated with these 'attacks', high discharge rates were displayed (Fig. 7). This was expected since in earlier work (Kramer and Bauer, 1976) a discharge rate increase was found to accompany every attack on other fish.

Another type of EOD response displayed during social behaviour was also shown towards the active dipole model. G. petersii had been found statistically to prefer a discharge delay of approx. 9-13 ms latency to foreign pulses (Preferred Latency Response: Bauer and Kramer, 1974; Kramer, 1974; Russell et al., 1974). Very strong Preferred Latency Responses (of up to $36 \%$ EODs within the above latency range) were also found in the present experiments with both stimulus patterns. No systematic trend for one of the two stimulation patterns to elicit more Preferred Latency Responses than the other could be detected. 
Table 1. Startle response rates displayed by seven $G$. petersii inside their porous-pot hiding-places during stimulation with rest pattern A and attack pattern B. Asterisks: no startle responses were observed since the fish immediately left its hiding-place at stimulation onset. The bar graphs show the means together with their \pm 1 standard error ranges separately for each fish. Note that during stimulation with attack pattern B, each fish displayed a higher startle response rate compared with stimulation with rest pattern A. The data were tested for significance of differences by the randomization test for matched pairs. Pooling of data yielded $P \ll 0.001$

\begin{tabular}{|c|c|c|c|c|c|c|c|c|c|c|c|c|c|c|}
\hline \multicolumn{15}{|l|}{ Startle responses/s } \\
\hline Fish & A & & $\mathrm{C}$ & & $\mathrm{D}$ & & $\mathrm{E}$ & & $\mathrm{F}$ & & $\mathrm{G}$ & & $\mathrm{H}$ & \\
\hline Stimulation pattern & $\mathbf{B}$ & $\mathrm{A}$ & $\mathrm{B}$ & A & B & A & $\mathrm{B}$ & $\mathrm{A}$ & $\mathrm{B}$ & A & B & A & B & A \\
\hline Day 1 & 0.48 & 0.37 & 0.42 & 0.03 & 0.60 & 0.34 & 0.43 & 0.25 & 0.30 & 0.16 & 0.19 & 0.07 & 0.07 & 0.05 \\
\hline Day 2 & 0.39 & 0.20 & 0.20 & 0.08 & 0.20 & 0.17 & 0.37 & 0.14 & 0.25 & 0.18 & 0.22 & 0.07 & 0.12 & 0.05 \\
\hline Day 3 & $*$ & $*$ & 0.18 & 0.04 & 0.33 & 0.14 & 0.19 & 0.05 & 0.23 & 0.18 & 0.13 & 0.09 & 0.06 & 0.03 \\
\hline Day 4 & $*$ & * & 0.18 & 0.07 & 0.28 & 0.25 & 0.19 & 0.09 & 0.31 & 0.25 & 0.12 & 0.05 & 0.11 & 0.04 \\
\hline Day 5 & $*$ & $*$ & 0.15 & 0.08 & - & - & 0.20 & 0.08 & 0.29 & 0.20 & 0.14 & 0.06 & 0.13 & 0.04 \\
\hline
\end{tabular}

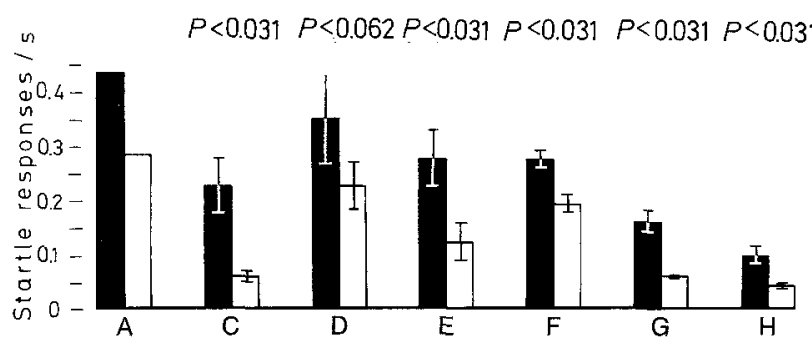

Figures 8 and 9 show the discharge rate responses of fish $\mathrm{A}$ to the onset of stimulation with the rest pattern and the attack pattern. In both records, an EOD rate increase was observed at the onset of stimulation with the dipole (broken lines). While in Fig. 9 there were 15 clear-cut EOD rate increases ( $>60 \mathrm{~Hz}$ ) at dipole pulse rate increases within approx. $180 \mathrm{~s}$ shown, there were only two such weak responses $(>40 \mathrm{~Hz})$ in Fig. 8. In Fig. 9, three of the EOD rate increases were followed by sharp discharge rate decreases or discharge breaks (at 30,50, and $116 \mathrm{~s}$ ). In three instances, a very low discharge rate or a mo- mentary discharge break was displayed before an EOD rate increase (at 81, 116, and $168 \mathrm{~s}$ ). At $51 \mathrm{~s}$, a short discharge break instead of an EOD rate increase was displayed on a dipole pulse rate increase.

In order to reduce the amount of verbal description necessary to characterize the EOD responses of the fish to stimulation, the autocorrelation and spectral analysis methods outlined in Materials and Methods were applied to the data. In addition, crosscorrelation from the EOD responses to the stimulus patterns was performed. In each analysis, the first $10 \mathrm{~s}$ of EOD activity following onset of stimulation were omitted since visual inspection of the data suggested that the fish did not respond very differently to the two kinds of stimulation patterns during that time.

Autocorrelation analysis of the EOD rates displayed by the fish during stimulation invariably yielded positive correlation coefficients for adjacent data points, with a decline to zero as more data points separated the two points considered (Fig. 10). How-

Table 2. Attack responses of seven G. petersii on the dipole model during 3 min of stimulation with rest pattern $\mathrm{A}$ and attack pattern B. Asterisks: the fish did not leave their porous-pot hiding-places during the whole stimulation period. Attack rates were significantly greater during attack pattern stimulation individually for fish $\mathrm{A}$, and for the paired attack totals of all fish $(P<0.05$, randomization test for matched pairs)

Attack responses on the dipole model

\begin{tabular}{lcccccccccccccc}
\hline Fish & A & & C & & D & & E & & F & & G & H \\
\hline Stimulation pattern & B & A & B & A & B & A & B & A & B & A & B & A & B & A \\
\hline Day 1 & 10 & 2 & 8 & $0^{*}$ & 0 & 0 & 5 & 0 & 2 & 0 & $0^{*}$ & $0^{*}$ & $0^{*}$ & $0^{*}$ \\
Day 2 & 27 & 0 & 1 & $0^{*}$ & 0 & 0 & 0 & $0^{*}$ & 1 & 0 & $0^{*}$ & $0^{*}$ & $0^{*}$ & $0^{*}$ \\
Day 3 & 24 & 9 & $0^{*}$ & $0^{*}$ & 0 & 0 & 0 & 0 & 0 & 0 & $0^{*}$ & $0^{*}$ & $0^{*}$ & $0^{*}$ \\
Day 4 & 21 & 5 & 0 & $0^{*}$ & $0^{*}$ & $0^{*}$ & 2 & 0 & 0 & 0 & $0^{*}$ & $0^{*}$ & $0^{*}$ & $0^{*}$ \\
Day 5 & 23 & 13 & 7 & 0 & - & - & 3 & 0 & 0 & 0 & $0^{*}$ & $0^{*}$ & 4 & $0^{*}$ \\
\hline
\end{tabular}




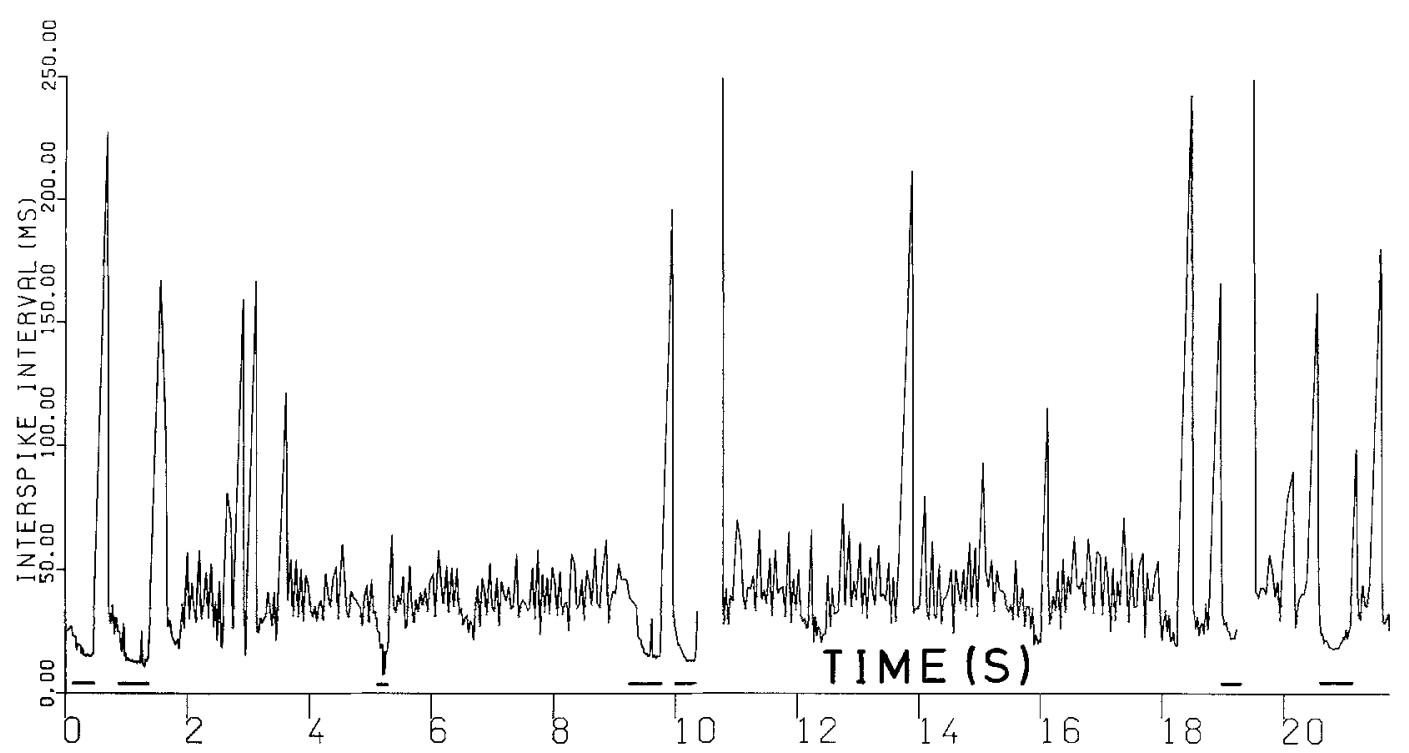

Fig. 7. EOD activity of $G$. petersii during stimulation with social signals (attack pattern B). The abscissa of each point is the time of occurrence (s) of each discharge, and the ordinate is the interval (ms) from the previous discharge. High discharge rates (underlined by horizontal bars) and attack responses were elicited by high pulse rates of the stimulating dipole model

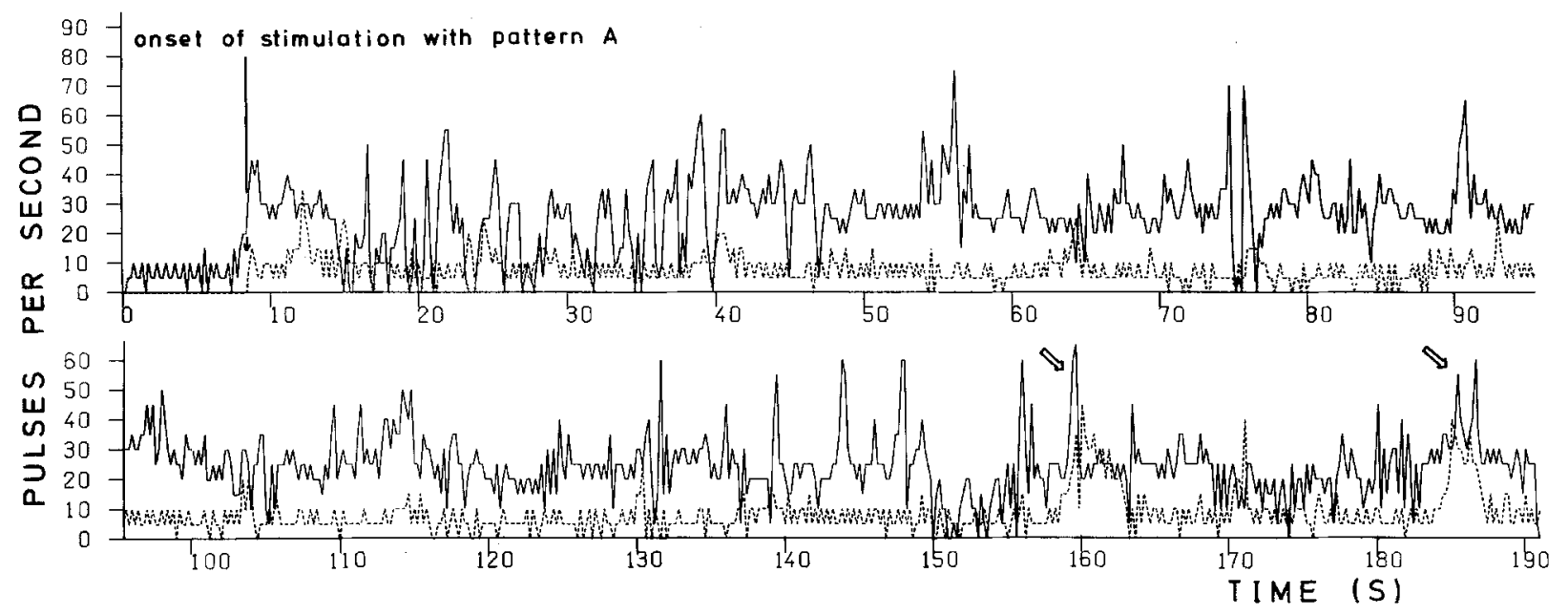

Fig. 8. Concurrent pulse rates of $G$. petersii and of the dipole model driven with rest pattern A. Abscissa: time (s); ordinate: pulse rates measured during successive 0.2-s time intervals (expressed in $\mathrm{Hz}$ ). The onset of stimulation (broken line) at $9 \mathrm{~s}$ is indicated by an arrow. The whole sequence is cut into two parts, the lower part continues the upper. White arrows indicate two instances where a stimulus pulse rate increase coincided with an EOD rate increase. Note that these instances were rare compared with Fig. 9

ever, several parameters of the EOD activities of the experimental subjects significantly depended on the type of stimulation pattern used. The correlation between adjacent data points was stronger when the fish were stimulated with rest pattern A (average correlation of 0.67 ) than when they were stimulated with attack pattern B (average correlation of 0.61 ; $P<0.02$, paired $t$-test, Wilcoxon matched-pairs signedranks test, Fig. 11). Also the number of correla- tion coefficients significant at $P<0.001$ was greater during rest pattern stimulation (on the average 9.7) than during attack pattern stimulation (on the average 6.2; $P<0.01$, Wilcoxon matched-pairs signed-ranks test, Fig. 11).

Other parameters of the discharge activities also depended on the kind of stimulus pattern used. The peaks of the pulse rate histograms were on significantly different positions of the $\mathrm{Hz}$ scale during rest 


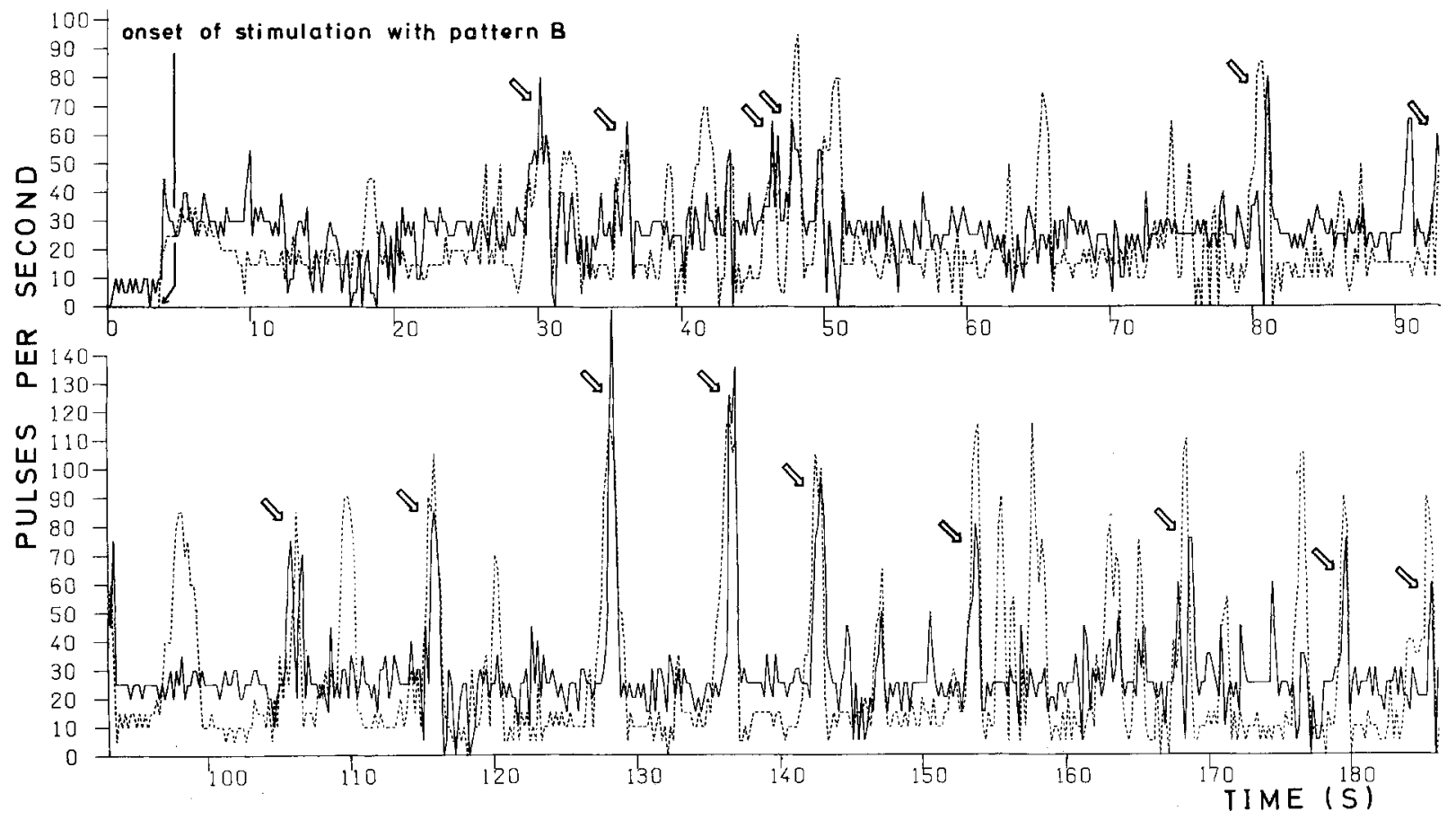

Fig. 9. Shows the same as Fig. 8 but for stimulus pattern B. Note that the instances of EOD rate increases elicited by stimulus pulse rate increases (white arrows) were observed much more often than during stimulation with rest pattern A (Fig. 8)
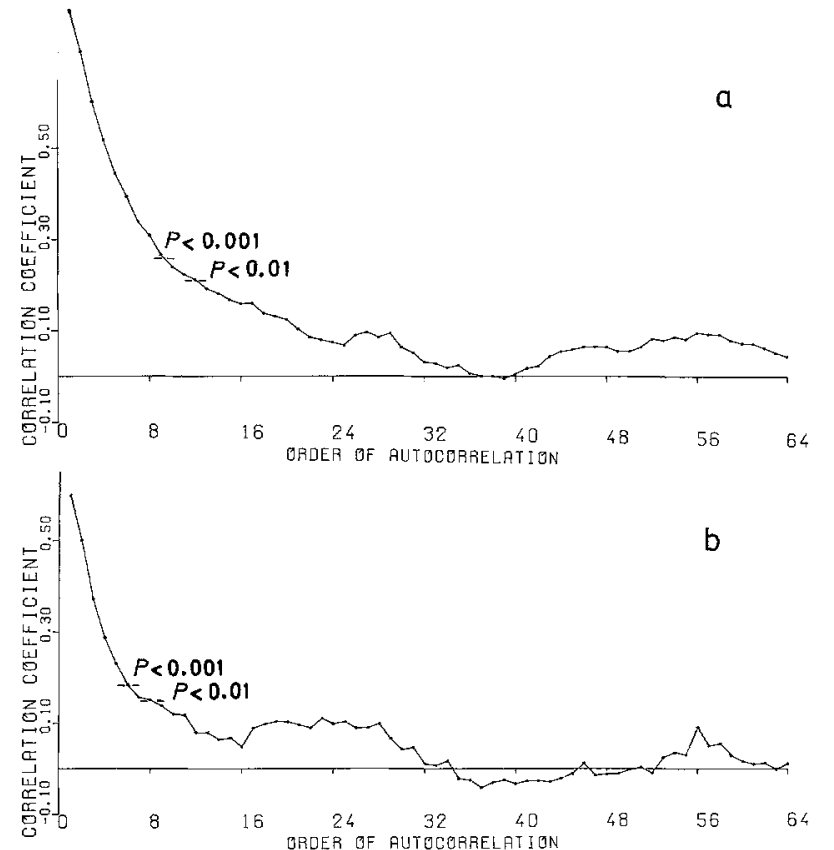

Fig. 10 a and $b$. Autocorrelation analysis of the EOD rate responses of $G$. petersii to (a) stimulation with rest pattern A and (b) stimulation with attack pattern B. Note that the autocorrelation function of the EOD responses start with a higher coefficient in a than in b. Discharge rate correlation 'died out' at a greater lag or order of autocorrelation in $\mathbf{a}(1.8 \mathrm{~s} ; k=9)$ than in $\mathbf{b}(1.2 \mathrm{~s} ; k=6)$. Data were taken from one fish and the same day

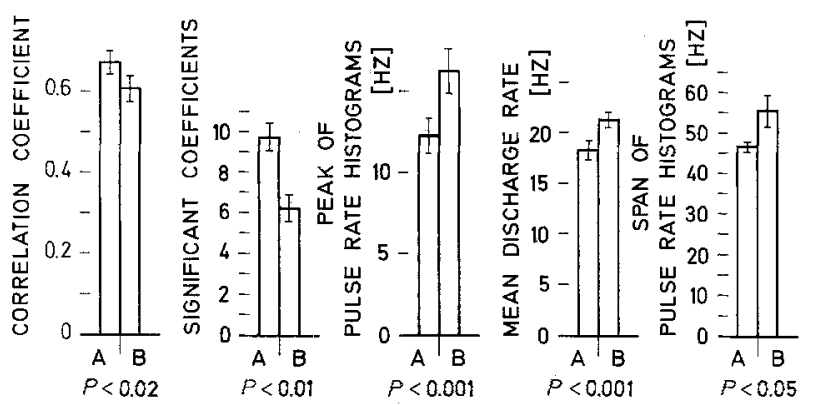

Fig. 11. Statistical comparison of autocorrelation and of pulse rate parameters of the EOD activities displayed by seven $G$. petersii during rest stimulation with pattern A (left columns) and pattern $\mathrm{B}$ (right columns). The means $(n=23)$ are shown together with their \pm 1 standard error ranges. The levels of significance of differences between paired series of experiments are indicated below the base line. Note that the correlation between adjacent data points was stronger and that the number of significant coefficients $(P<0.001)$ was greater during rest pattern stimulation compared with attack pattern stimulation. The modes of the pulse rate distributions were on different positions of the $\mathrm{Hz}$ scale, and also the mean EOD rates differed significantly. The ranges of pulse rates observed (i.e., the span from the lowest to the highest rates) were greater during attack pattern stimulation than during rest pattern stimulation. The data were analyzed by the paired $t$-test except the second pair of columns (from the left) which was analyzed by the Wilcoxon matched-pairs signed-ranks test 

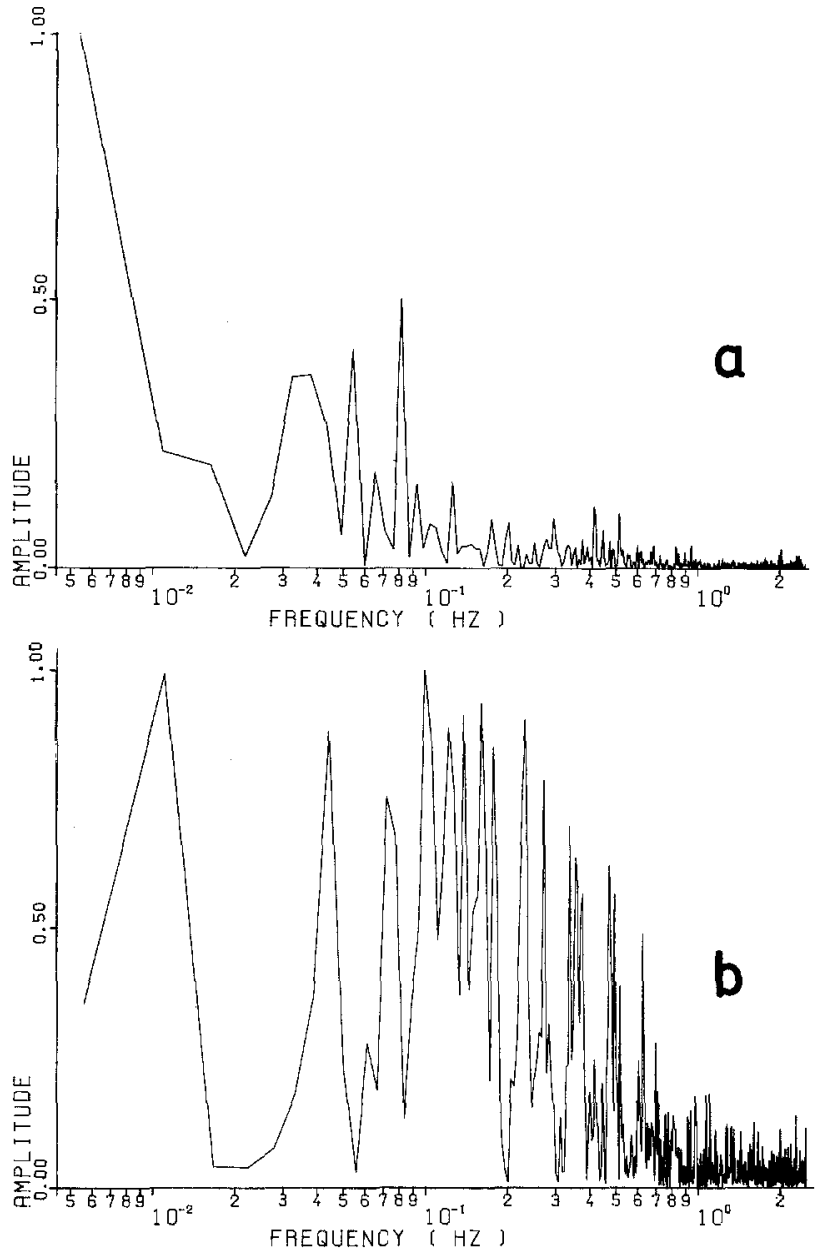

Fig. 12a and b. Amplitude spectrum analysis of the discharge rate fluctuations of $G$. petersii during stimulation with rest pattern $A$ (a) and attack pattern B (b). Note that during stimulation with the attack pattern $G$. petersii displayed considerably higher frequencies of discharge rate changes than during stimulation with the rest pattern. Data were taken from one fish and the same day

pattern stimulation (average $12.3 \mathrm{~Hz}$ ) and during attack pattern stimulation (average $16.2 \mathrm{~Hz} ; P<0.001$, paired $t$-test, Fig. 11). Similar differences $(18.2 \mathrm{~Hz}$ and $21.3 \mathrm{~Hz}$, respectively) were obtained for the mean discharge rates $(P<0.001$, paired $t$-test, Fig. 11). The number of non-empty bins or the spans of the pulse rate histograms comprised an average $47 \mathrm{~Hz}$ during rest pattern stimulation, and an average $56 \mathrm{~Hz}$ during attack pattern stimulation $(P<0.05$, paired $t$-test, Fig. 11).

The finding that the number of positive correlation coefficients was greater during rest pattern stimulation than during attack pattern stimulation (Fig. 11) shows that the periods of time for which similar discharge rates were maintained were longer during rest

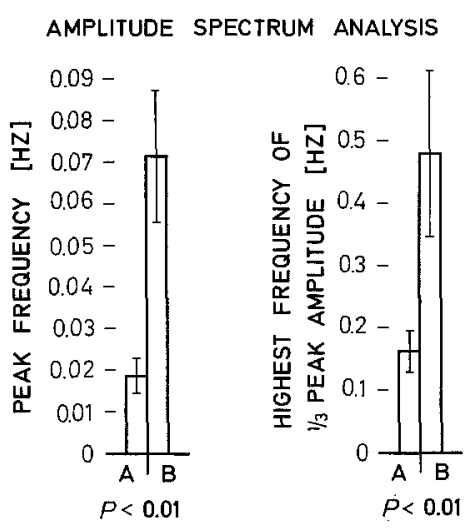

Fig. 13. Comparison of two amplitude-spectrum parameters of the EOD rate fluctuations of seven $G$. petersii during stimulation with rest pattern A (left columns) and attack pattern B (right columns). The means $(n=23)$ are shown together with their \pm 1 standard error ranges. The levels of significance of differences between paired series of experiments are indicated below the baseline (Wilcoxon matched-pairs signed-ranks test). Note that the mean peak frequency and the mean of the highest $1 / 3$ peak frequency were significantly lower during rest pattern stimulation compared with attack pattern stimulation

pattern stimulation than during attack pattern stimulation. Spectral analysis confirmed that the discharge rates fluctuated at different frequencies. Two examples from the same fish on the same day are shown in Fig. 12. While during rest pattern stimulation very low frequencies prevailed (the highest frequency of $1 / 3$ peak amplitude was $0.082 \mathrm{~Hz}$ ), during attack pattern stimulation a $1 / 3$ peak amplitude was still found at $0.63 \mathrm{~Hz}$. The means of the peak frequencies were near $0.02 \mathrm{~Hz}$ during rest pattern stimulation and approx. $0.07 \mathrm{~Hz}$ during attack pattern stimulation $(P<0.01$, Wilcoxon matched-pairs signed-ranks test, Fig. 13). The highest frequencies of $1 / 3$ peak amplitude were on the average $0.16 \mathrm{~Hz}$ during rest pattern stimulation and $0.48 \mathrm{~Hz}$ during attack pattern stimulation $(P<0.01$, Wilcoxon matched-pairs signed-ranks test, Fig. 13). No significant differences were found when the lowest frequencies of $1 / 3$ peak amplitude were compared for rest pattern and attack pattern stimulation (Wilcoxon matched-pairs signed-ranks test; $P \gg 0.20$, paired $t$-test).

Several significant differences in the responses of the fish to the two stimulation patterns were also found by cross-correlation of the EOD activities with the stimulus patterns.

Examples of the results are shown in Fig. 14. The cross-correlations from the EOD responses of the fish to the stimulus patterns were weaker during rest pattern stimulation (average maximal cross-correlation of 0.2 ) than during attack pattern stimulation (average maximal cross-correlation of $0.33 ; P<0.001$, paired $t$-test, Fig. 15). However, the number of signifi- 

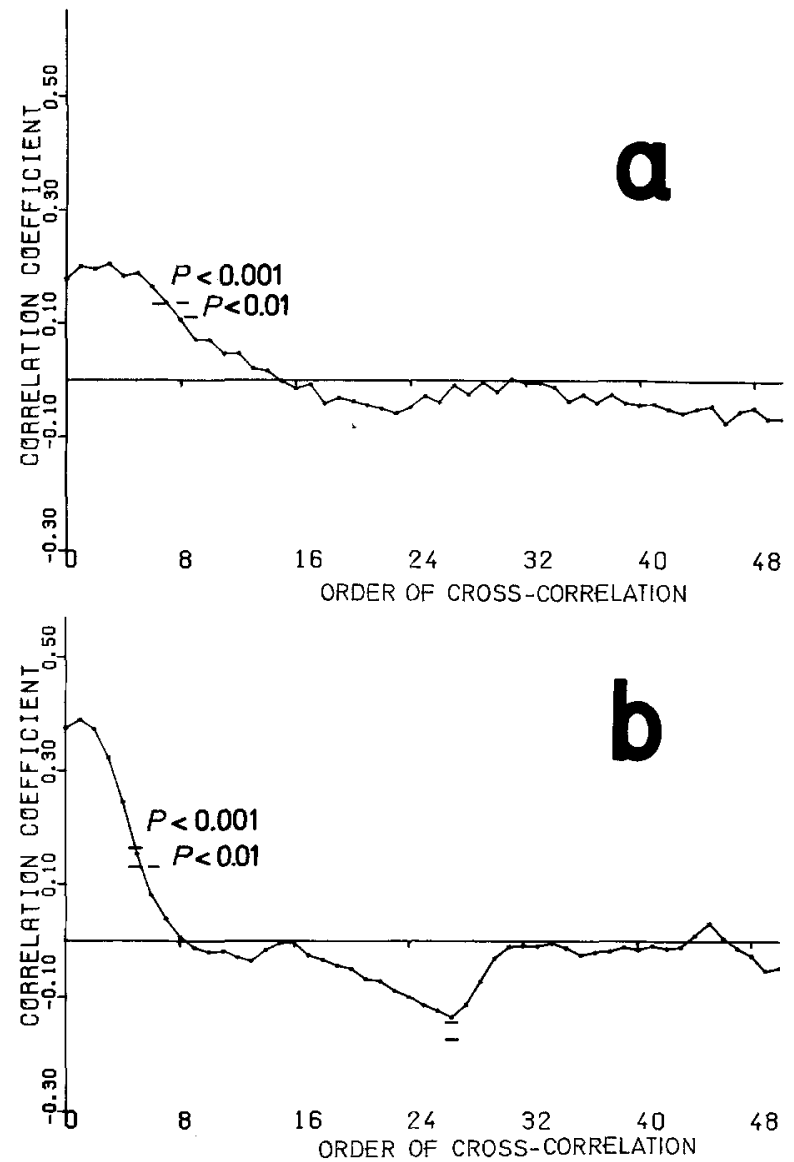

Fig. 14 a and b. Cross-correlation analysis of the EOD rate responses of $G$. petersii to (a) stimulation with rest pattern $\mathrm{A}$ and (b) stimulation with attack pattern $B$. Note that the strongest cross-correlation in a was weaker and occurred at a greater lag or order of crosscorrelation $(0.6 \mathrm{~s} ; k=3)$ than in $\mathbf{b}(0.2 \mathrm{~s} ; k=1)$. However, significant cross-correlation $(P<0.001)$ was maintained for a longer period of time in a $(1.4 \mathrm{~s} ; k=7)$ than in $\mathbf{b}(0.8 \mathrm{~s} ; k=4)$. Data were taken from the same fish and day

cant $(P<0.001)$ cross-correlation coefficients of either sign was greater during rest pattern stimulation (average 8.9) than during atack pattern stimulation (average $4.6 ; P<0.01$ ), Wilcoxon matched-pairs signed-ranks test, Fig. 15). A similar result was found when only the positive cross-correlation coefficients were considered (rest pattern stimulation: an average number of 6.8 coefficients were significant; attack pattern stimulation: an average number of 3.9 coefficients were significant; difference significant at $P<0.01$, Wilcoxon matched-pairs signed-ranks test, Fig. 15). No significant differences between the numbers of negative cross-correlation coefficients (significant at $P<0.01$ ) were found for the two stimulation patterns.

Cross-correlation was not only weaker during rest pattern stimulation compared with attack pattern stimulation, but the lag of the maximal cross-correla-
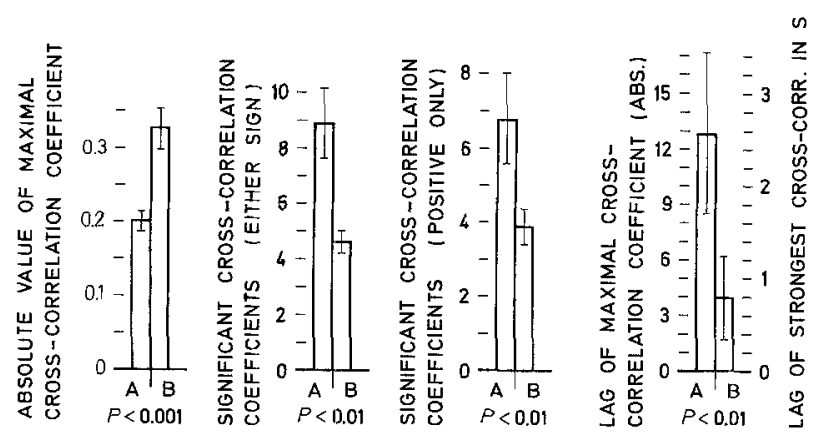

Fig. 15. Statistical comparison of various parameters of the crosscorrelations from the rest pattern A (left columns) and the attack pattern B (right columns) to the EOD rate responses of seven G. petersii. The means $(n=23)$ are shown together with their \pm 1 standard error ranges. The levels of significance of differences between paired series of experiments are shown below the base line. Note that the maximal cross-correlation coefficient (taken as the absolute value) is lower but that the number of significant coefficients $(P<0.001)$ is greater during rest pattern stimulation compared with attack pattern stimulation. The lags of maximal crosscorrelation to the stimulus patterns were approx. $2.6 \mathrm{~s}$ during rest pattern stimulation, and $0.8 \mathrm{~s}$ during attack pattern stimulation. The data were analyzed by the paired $t$-test (left pair of columns), and by the Wilcoxon matched-pairs signed-ranks test (all other pairs of columns)

tion was also greater. During rest pattern stimulation an average lag near $2.6 \mathrm{~s}$ was found; during attack pattern stimulation the average lag was only $0.8 \mathrm{~s}$ $(P<0.01$, Wilcoxon matched-pairs signed-ranks test, Fig. 15).

\section{Discussion}

Time series analysis methods were extensively used in the present work in order to detect differences in response patterns to two kinds of stimulation patterns. It was shown that these methods were able to quantify characteristic parameters for both the stimulation and the response patterns.

The results clearly showed that $G$. pertersii distinguished the two types of conspecific discharge time patterns, resting EOD activity (pattern A) and agonistic (attacking) EOD activity (pattern B), since motor as well as electric responses were significantly different for both stimulation patterns. It has to be kept in mind, however, that the attack pattern used in this study had been recorded from a $G$. petersii attacking a Mormyrus rume, a mormyrid fish displaying distinct EOD patterns (Kramer, 1976a). A comparison with the EOD interaction observed in pairs of G. petersii (Moller and Bauer, 1973; Bell et al., 1974) showed that the EOD patterns of a G. petersii attacking a $M$. rume are very similar to those, especially the attack-associated discharge rate increases and 
high discharge rates (which seem to be the important parts of the signal; see below). Thus it appears justified to conclude that at least two specific time patterns of pulses encode different 'messages' in the intraspecific communication system of $G$. petersii. It would be intersting to know whether $G$. petersii would also recognize two other types of EOD patterns: swimming (locomotory) EOD activity (Kramer and Bauer, 1976), and fleeing EOD activity during agonistic behaviour (Kramer, 1976b).

The relationships between stimulus patterns and response patterns do not seem to be simple. While the pulse rate histogram data (Fig. 11) might partly be explained by a very simple 'imitation model' (a stimulation pattern with a broad distribution of pulse rates, shown in Fig. 3 b, elicited a similarly broad response distribution of pulse rates) no such hypothesis can be maintained for part of the autocorrelation results of the same data. The correlations between adjacent data points were stronger during rest pattern stimulation than during attack pattern stimulation (Figs. 10 and 11), although for the two stimulation patterns the reverse results had been found (Fig. 4). Despite this, the periods of time of positive correlations of the EOD response patterns were longer during rest pattern stimulation $(2 \mathrm{~s})$ than during attack pattern stimulation (1.2 s, Fig. 11), and thus approximately matched properties of the stimulation patterns (rest pattern: $2 \mathrm{~s}$; attack pattern: $0.8 \mathrm{~s}$, Fig. 4). In a similar fashion, high frequencies of discharge rate changes were elicited by the attack pattern (Figs. 12 and 13), itself characterized by a high-frequency content (Fig. $5 \mathrm{~b}$ ). Surprisingly, the rapidly fluctuating attack pattern was shown to exert a considerably stronger influence on the response pattern than did the rest pattern, as measured by cross-correlation (Figs. 14 and 15). In addition, this stronger correlation occurred at a shorter lag. This presumably shows that rapid discharge-rate changes may be among the important 'features' that are detected by the fish and that influence arousal and motivational state.

Among other possibilities, this hypothesis can be tested by the experimental use of a synthetic stimulation pattern combining some properties of the rest pattern (EOD interval distribution, and thus EOD mean rate) with a high frequency spectrum of discharge rate changes, a property of the attack pattern, by appropriately rearranging the EOD interval sequence. In this way the effects of the stimulus pulse mean rate (which was lower in the rest pattern than in the attack pattern, Fig. 3) could probably be distinguished from the effects of a spectrum of high frequencies of stimulus pulse rate changes alone.
Acknowledgments. This work was supported by research grants $\mathrm{Kr}$ 446/4-6 from the Deutsche Forschungsgemeinschaft. I wish to thank Prof. Dr. W.T. Keeton and Prof. Dr. H. Markl for valuable suggestions and critically reading the manuscript, and H.-J. Burger for expert technical assistance.

\section{References}

Bauer, R.: High electrical discharge frequency during aggressive behaviour in a mormyrid fish, Gnathonemus petersii. Experientia 28, 669 (1972)

Bauer, R.: Electric organ discharge activity of resting and stimulated Gnathonemus petersii (Mormyridae). Behaviour 50, 306-323 (1974)

Bauer, R., Kramer, B.: Agonistic behaviour in mormyrid fish: Latency-relationship between the electric discharges of $\mathrm{Gna}$ thonemus petersii and Mormyrus rume. Experientia 30, 51-52 (1974)

Belbenoit, P.: Relations entre la motricité et la décharge électrique chez les Mormyridae (Teleostei). J. Physiol. Paris 65, 197 A (1972)

Bell, C.C, Myers, J.P., Russell, C.J.: Electric organ discharge patterns during dominance related behavioural displays in Gnathonemus petersii (Mormyridae). J. Comp. Physiol. 92, 201-228 (1974)

Boudinot, M.: Contribution à l'étude des caractéristiques électriques de l'organe effecteur de Gnathonemus petersii. Mémoire présenté au conservatoire national des Arts et métiers pour obtenir le diplôme d'ingénieur C.N.A.M., Paris 1972

Box, G.E.P., Jenkins, G.M.: Time series analysis: Forecasting and control. San Francisco: Holden Day 1976

Harder, W., Schief, A., Uhlemann, H.: Zur Empfindlichkeit des schwachelektrischen Fisches Gnathonemus petersii (Gthr.1862) (Mormyriformes, Teleostei) gegenüber elektrischen Feldern. Z. Vergl. Physiol. 54, 89-108 (1967)

Heiligenberg, W.: Electrolocation and jamming avoidance in the mormyrid fish Brienomyrus. J. Comp. Physiol. 109, 357-372 (1976)

Heiligenberg, W. : Principles of electrolocation and jamming avoidance in electric fish. A neuroethological approach. In: Studies of brain function, Vol. 1. Braitenberg, V., Barlow, H.B., Florey, E., Grüsser, O.-J., Loos, H. van der (eds.). Berlin, Heidelberg, New York: Springer 1977

Kramer, B.: Electric organ discharge interaction during interspecific agonistic behaviour in freely swimming mormyrid fish. A method to evaluate two (or more) simultaneous time series of events with a digital analyser. J. Comp. Physiol. 93, 203-235 (1974)

Kramer, B. : Electric signalling during aggressive behaviour in Mormyrus rume (Mormyridae, Teleostei). Naturwissenschaften 63, 48 (1976a)

Kramer, B.: Flight-associated discharge pattern in a weakly electric fish, Gnathonemus petersii (Mormyridae, Teleostei). Behaviour 59, 88-95 (1976b)

Kramer, B.: The attack frequency of Gnathonemus petersii towards electrically silent (denervated) and intact conspecifics, and towards another mormyrid (Brienomyrus niger). Behav. Ecol. Sociobiol. 1, 425-446 (1976c)

Kramer, B.: Spontaneous discharge rhythms and social signalling in the weakly electric fish, Pollimyrus isidori (Cuvier et Valenciennes) (Mormyridae, Teleostei). Behav. Ecol. Sociobiol. 4, 61-74 (1978)

Kramer, B., Bauer, R.: Agonistic behaviour and electric signalling 
in a mormyrid fish, Gnathonemus petersii. Behav. Ecol. Sociobiol. 1, 45-61 (1976)

Möhres, F.P.: Elektrische Entladungen im Dienste der Revierabgrenzung bei Fischen. Naturwissenschaften 44, 431-432 (1957)

Moller, P.: 'Communication' in weakly electric fish, Gnathonemus niger (Mormyridae). I. Variation of electric organ discharge (EOD) frequency elicited by controlled electric stimuli. Anim. Behav. 18, 768-786 (1970)

Moller, P.: Electric signals and schooling behaviour in a weakly electric fish, Marcusenius cyprinoides L. (Mormyriformes). Science 193, 697-699 (1976)

Moller, P., Bauer, R.: 'Communication' in weakly electric fish, Gnathonemus petersii (Mormyridae). II. Interaction of electric organ discharge activities of two fish. Anim. Behav. 21, 501-512 (1973)

Russell, C.J., Myers, J.P., Bell, C.C.: The echo response in Gna- thonemus petersii (Mormyridae). J. Comp. Physiol. 92, 181-200 (1974)

Sänger, K.: Ein Beitrag zur Klärung der Rolle der Entladungen des elektrischen Organs im Verhalten von Gnathonemus petersii (Gthr 1862) (Mormyriformes, Teleostei). Sitzungsber. Oesterr. Akad. Wiss. Math. Naturwiss. Kl., Abt. I, 180, 29-48 (1972)

Serrier, J.: Modifications instanées du rythme de l'activité électrique d'un Mormyre, Gnathonemus petersii, provoquées par la stimulation électrique artificielle de ses électrorécepteurs. J. Physiol. Paris 66, 713-728 (1973)

Siegel, S.: Nonparametric statistics for the behavioral sciences. New York: McGraw-Hill 1956

Szabo, T., cited by Lissmann, H.W. : Ecological studies on gymnotids. In: Bioelectrogenesis. Chagas, C., Paes de Carvalho, A. (eds.), pp. 215-226. Arnsterdam: Elsevier 1961 